\title{
Toxic thermoresistant metabolites of Fusarium oxysporum are capable of inducing histopathological alterations in Wistar rats
}

\author{
Hernandes L (1), Marangon AV (1), Salci T (1), Svidzinski TIE (2)
}

(1) Laboratory of Histology, Department of Morphological Sciences, State University of Maringá (UEM), Maringá, Paraná State, Brazil; (2) Department of Clinical Analysis, Laboratory of Medical Mycology, State University of Maringá (UEM), Maringá, Paraná State, Brazil.

\begin{abstract}
The genus Fusarium is known to produce mycotoxins that cause fusariosis in plants, animals and humans. Mycotoxins are among the virulence factors of this genus. Metabolic extracts of Fusarium oxysporum, isolated from a patient with onychomycosis and sterilized by filtration or autoclave, were inoculated intradermally into Wistar rats at concentrations of $0.25,0.5$ and $1 \mu \mathrm{g} / \mu \mathrm{L}$, and the effects on their tegument were observed at 24 and 72 hours. After histological procedures and staining by hematoxylineosin, the sections were studied for their inflammatory-reaction intensity and for evidence of injury and tissue distortion. Inflammatory reactions in the dermis and the subcutaneous tissue were observed at all concentrations of the inoculated extract tested. There was a significant influx of neutrophils, mastocytes and lymphocytes, as well as a large quantity of macrophages. Apoptotic bodies and hyperemic blood vessels were observed. This reaction was directly related to the extract concentration, and was most intense in animals that received the $1 \mathrm{mg} / \mu \mathrm{L}$ dose. The maximum peak was observed at 24 hours. The autoclaved metabolic extract produced the same effects as the untreated one, indicating the presence of heat-resistant metabolites. In conclusion, the metabolic extracts obtained from sterilized culture filtrates of $F$. oxysporum are capable of inducing an inflammatory response within 24 hours in the dermis and subcutaneous tissue of rats.
\end{abstract}

Key words: fungal skin disease, Fusarium, mycotoxins.

\section{INTRODUCTION}

Species of Fusarium are responsible for serious contagious infections with high mortality rates, usually involving immunocompromised patients (1-3). The tegumentary lesions caused by Fusarium tend to manifest as erythematous and nodular papules with central necrosis (4). In immunocompetent individuals, the lesions tend to be localized and manifested as keratitis and onychomycosis, while maintaining a clinical pattern that suggests an inflammatory response (5-9).

The unique susceptibility of each host is a determining factor in the establishment of infections by Fusarium, but it is also evident that this fungus possesses its own attributes that enable it to invade healthy tissues, provoking inflammatory reactions and allowing it to spread to other areas. Metabolites such as lytic enzymes and toxic substances, known as mycotoxins, are prominent among the virulence factors of members of this genus $(6,10-12)$. Fusarium also produces phytotoxins, antibiotics and pigments (13).

The known chemical and physical properties of some Fusarium metabolites include their solubility, polarity and thermal resistance (1416). The pathogenicity of the metabolites has been studied in plants, but little is known about their action mechanism in animal tissues (13). 
On the other hand, it is well known that the filtering process guarantees the absence of microorganisms in the sample. In a previous study we demonstrated that filtered Fusarium oxysporum extract induced an inflammatory response and programmed cell death in rat skin (17). However, the effect of thermal sterilization on the biological activity of the extract is not known. Therefore, we studied the effects of metabolites produced by Fusarium oxysporum, isolated from human onychomycosis, on the tegument of rats, by comparing metabolic extracts sterilized by filtration and by autoclaving.

\section{MATERIALS AND METHODS}

\section{Microorganisms and Culture Conditions}

The Fusarium oxysporum fungus was previously isolated from a patient-carrier of onychomycosis in a dermatology clinic and sent to the Laboratory of Teaching and Research in Clinical Analyses (LEPAC) at the State University of Maringá, Paraná state, Brazil. The patient presented yellowish-white nails with proximal involvement, associated with periungual pain and inflammation (9).

The metabolic extracts were obtained based on the protocol of Melo and Piccinin (18). The fungus was transferred to Petri dishes containing potatodextrose agar (Difco, USA) culture medium. After incubation for seven days at $25^{\circ} \mathrm{C}$, three disks of $5 \mathrm{~mm}$ diameter from these cultures were placed in $200 \mathrm{~mL}$ of previously sterilized liquid Czapek-Dox medium $\left(0.5 \mathrm{~g} \mathrm{KCl}, 1 \mathrm{~g} \mathrm{KH}_{2} \mathrm{PO}_{4}\right.$ $2 \mathrm{~g} \mathrm{NaNO}_{3}, 30 \mathrm{~g}$ saccharose, $0.01 \mathrm{~g} \mathrm{FeSO}_{4}, \mathrm{H}_{2} \mathrm{O}$, and $0.5 \mathrm{~g} \mathrm{MgSO}_{4}, 7 \mathrm{H}_{2} \mathrm{O}$ per $1000 \mathrm{~mL}$ of distilled water), $\mathrm{pH}$ adjusted to 5.5. The cultures were kept in an incubator at $25^{\circ} \mathrm{C}$ under orbital shaking at $70 \mathrm{rpm}$ for 15 days.

After this period, the cultures were filtered twice in Whatman n. 1 paper, using a vacuum pump, thus obtaining the fungal filtrate. The filtrate was divided into two portions; one sterilized by filtration in a Millipore filter (Bedford, USA) and the other sterilized by heat (autoclaved at $120^{\circ} \mathrm{C}$ for 20 minutes). Both were dialyzed against distilled water for 48 hours, lyophilized and stored at $4^{\circ} \mathrm{C}$ until use.

\section{In Vivo Inoculation}

All the experiments involving animals were approved by the Ethics Committee for Animal
Experimentation of the State University of Maringá.

Fourteen Wistar rats (Rattus norvegicus) weighing 170 to $180 \mathrm{~g}$ each were used. The animals were kept in individual cages in a temperature-controlled environment of $22 \pm 2{ }^{\circ} \mathrm{C}$ and 50\% humidity, with a 12-hour light/dark cycle and free access to water and food, for the entire experimental period.

The animals were anesthetized with thiopental (40 $\mathrm{mg} / \mathrm{kg}$ ) and the fur was manually removed from the cervical region of the back, where 100 $\mu \mathrm{L}$ of the extract, at different concentrations, was intradermally administered. The rats were divided into two groups: Group 1 received the extract obtained by filtration in the Millipore membrane at concentrations of $0.25,0.5$ and $1 \mu \mathrm{g} /$ $\mu \mathrm{L}$, whereas Group 2 received the extract obtained by autoclaving at the same concentrations. The animals were killed by an overdose of anesthetic at 24 or 72 hours. As a control for the tissue reaction, another group of animals was inoculated intradermally with $100 \mu \mathrm{L}$ of $0.85 \%$ physiological solution and maintained under the same conditions. The animals were observed for clinical manifestations of inflammatory effects.

\section{Histological Procedure}

The skin samples were spread out on cardboard, fixed with $4 \%$ buffered formalin solution for 24 hours and processed for embedding in paraffin. After being cut with a microtome, the semi-serial 5 - $\mu \mathrm{m}$ sections were stained by the hematoxylineosin (HE) technique.

\section{Microscopic Analysis}

The skin segments were analyzed, in an Olympus BX41 (Tokyo, Japan) optical microscope, for the morphology of the inflammatory infiltrate and for evidence of tissue injury and distortion.

\section{RESULTS}

In the clinical evaluation, no skin alterations were observed among rats inoculated with the F. oxysporum extracts. However, in the histopathological examination, alterations were evident at 24 hours.

In the control group (Figure $1-A$ ), no histopathological changes with regard to the type or number of cells were found.

At 24 hours, the animals of Group 2 (Figure1 


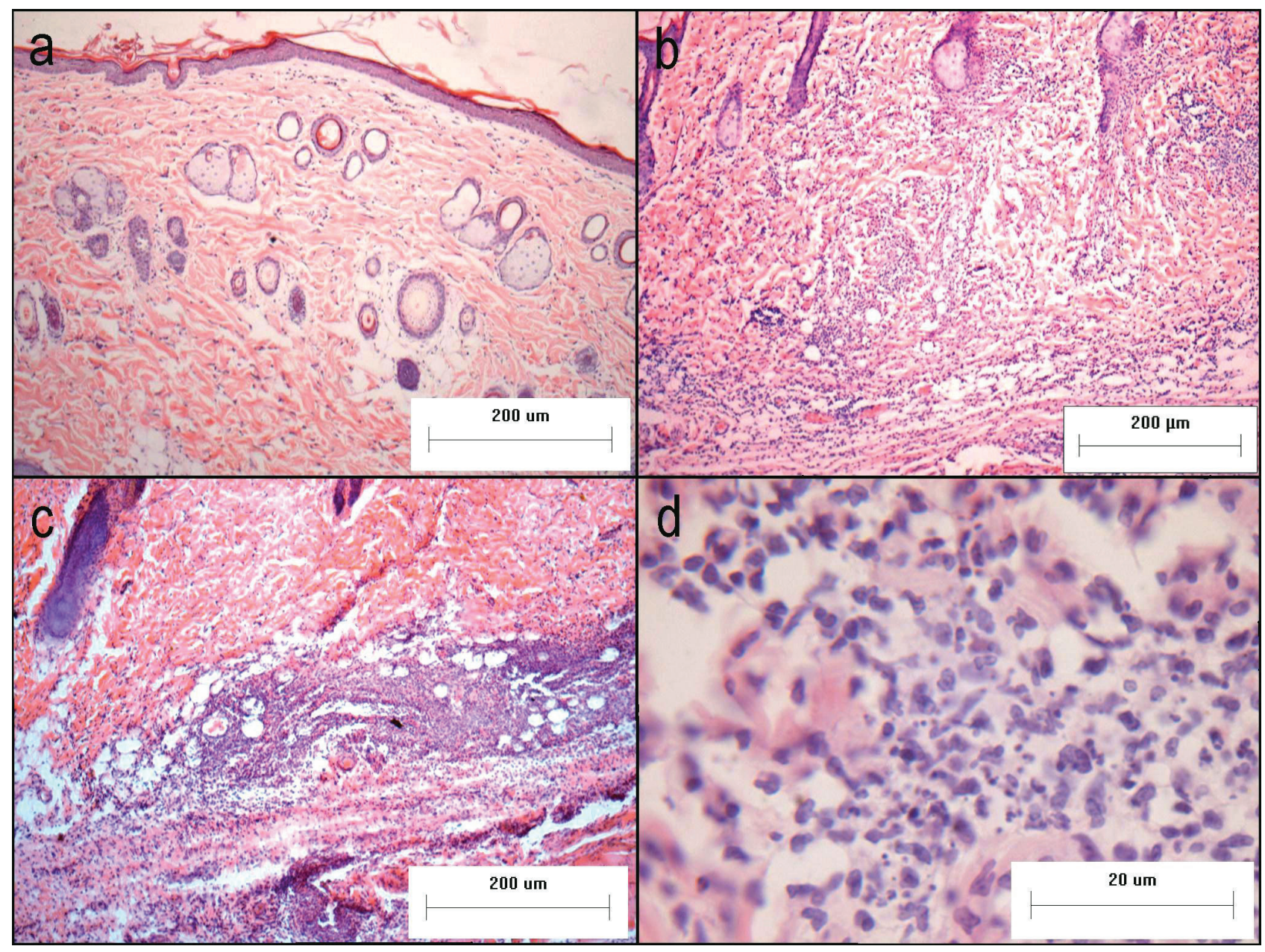

Figure 1. Photomicrographs of the skin of rats 24 hours after they were injected intradermally with: (a) $0.85 \%$ saline solution, (b) extract obtained by heat sterilization, (c) metabolic extract of $F$. oxysporum obtained by Millipore membrane sterilization, and (d) extract obtained by heat sterilization. (b) Moderate inflammatory reaction, (c) Intense inflammatory reaction, and (d) cells in apoptosis.

- B) showed a less intense inflammatory reaction profile. The reaction was directly proportional to the extract concentration, with a predominance of macrophages, followed by lymphocytes, in all the sections analyzed. An inflammatory reaction in the dermis and subcutaneous tissue of the animals from Group 1 was also observed (Figure $1-$ C). The presence of apoptotic bodies and cellular fragments was also widely noted, both in the dermis and in the subcutaneous tissue of Group 2 animals (Figure 1-D).

The reaction was more intense in the animals that received 0.5 or $1 \mu \mathrm{g} / \mu \mathrm{L}$ concentrations of the extract, compared to those that received the $0.25 \mu \mathrm{g} / \mu \mathrm{L}$ dose. The majority of the histological sections analyzed, at all the extract concentrations, presented mastocytes, lymphocytes, neutrophils and numerous macrophages. In addition to the presence of hyperemic blood vessels, large quantities of cellular fragments and apoptotic bodies were found.

After 72 hours, no further significant alterations were observed in either of the groups.

\section{DISCUSSION}

The results of the study revealed that metabolic extracts of $F$. oxysporum intradermally inoculated into the skin of rats are capable of provoking an acute tissue response in both the dermis and the subcutaneous tissue. Figure 1 shows the presence of inflammatory infiltrate (Figure 1 B and C) and apoptotic bodies (Figure $1-D$ ) in rat tegument. This potential inflammation is probably attributable to the presence of soluble extracellular substances that were excreted into the culture medium. 
This same type of extract, obtained from cultures of $F$. oxysporum in the plant studies of Melo and Piccinin (18), provoked reactions that produced withering in cucumber cells and plantlets, and cell death. Another study evaluating the effects of filtrates from different fungal species on the eclosion, motility and mortality of phytonematodes demonstrated that the F. oxysporum filtrate showed greater toxic activity than the filtrates obtained from other species (19).

The ability of $F$. oxysporum culture filtrates to induce biological effects would explain the inflammatory reaction observed in all patients who develop Fusarium-induced onychomycosis, which is not observed with other fungi, such as dermatophytes (9). This study, with a clinical isolate taken from a case of human onychomycosis, confirms the potential of this species to cause diseases in both plant and animal tissue (20). Several investigators have described a marked inflammatory reaction characterized by a necrotic aspect and accompanied by pain, in various human infections caused by Fusarium (6, 21-23).

The observed reactions cannot be attributed to the presence of the fungus, as the extracts were previously sterilized by filtration or by autoclaving. This suggests that soluble toxic metabolites are present in the extract.

Another important finding was that the autoclaved metabolic extract produced the same effects on rat tegument as the unheated extract, indicating the thermostable nature of these metabolites. Thermostability has been observed in many host-specific and non-host-specific toxins $(15,16)$.

The two F. oxysporum extracts induced the same type of reaction in rat tegument, albeit with a small quantitative reduction in dermatopathological alterations among the animals inoculated with the autoclaved extract. This suggests that some substances may be partially inactivated during heating. Nevertheless, at least some of the toxic components are preserved and remain active and capable of inducing an inflammatory response.

In both of the fungal extracts obtained by the two methods, the reaction intensity was dose-dependent. Twenty-four hours after inoculation, the response was proportional to the concentration of the extracts, being lowest at the concentration of $0.25 \mu \mathrm{g} / \mu \mathrm{L}$ and increasing proportionally in the animals that received 0.5 and $1 \mu \mathrm{g} / \mu \mathrm{L}$.

At 72 hours, the animals were able to control the action of both of the extracts. It is probable that the tissue response is associated with the virulence mechanism of Fusarium; however, the determination of the chemical nature and action mechanism of these fungal metabolites will depend on studies at the biochemical level. Such studies would enable a determination as to whether the observed effect is due to a single component or to an association and interaction of various substances.

There is a consensus that fungi, during their development in the host tissues or in culture media, may produce a variety of toxic secondary metabolites with varied biochemical structures and different action modes, including polypeptides, glycoproteins, amino acid derivatives, polyketides, terpenoids, sterols and quinines (24). The Czapeck-dox liquid medium, which is chemically defined, was suitable for stimulating the production of this type of metabolite produced by Fusarium, in accordance with reports by other investigators (18-25).

The extensive production of toxic metabolites in culture depends on each fungal isolate. Fungus producers of colored pigments in liquid cultures were more efficient at producing filtrates from biologically active cultures than those that did not produce color, suggesting that these pigments may be involved in the toxigenic action (24).

However, in the present experiment, pigment production was not important, as it was observed that a single fungal isolate, developed in aliquots of the same lot of Czapeck-dox medium and incubated for the same length of time, produced a pink color in some flasks but no pigmentation in others. When they were applied separately to the animals, the contents of all the flasks induced indistinguishable reactions (data not shown).

In may be concluded that the metabolic extracts obtained from sterilized culture filtrates of F. oxysporum are capable of inducing an inflammatory response within 24 hours in the dermis and subcutaneous tissue of rats. Seemingly, this effect would explain the pain and inflammatory reaction reported in lesions in humans. Furthermore, the toxic action observed was dose-dependent and attributable to a thermoresistant component. More detailed studies are required and should be developed 
with the objective of elucidating the chemical nature of the component or components involved in the inflammatory response, as well as aiming to understand and propose the action mechanism of these fungal metabolites.

\section{ACKNOWLEDEGMENTS}

The authors thank CAPES and CNPq for financial support, and are grateful to Maria Euride Carlo Cancino and Maria dos Anjos Fortunato for technical support.

\section{COPYRIGHT}

(C) CEVAP 2012

\section{SUBMISSION STATUS}

Received: June 28, 2011.

Accepted: October 21, 2011.

Abstract published online: October 26, 2011.

Full paper published online: May 31, 2012.

\section{CONFLICTS OF INTEREST}

The authors declare no conflicts of interest.

\section{FINANCIAL SOURCE}

The Coordination for the Improvement of Higher Education Personnel (CAPES) and The National Council for Scientific and Technological Development (CNPq) provided the financial grants.

\section{ETHICS COMMITTEE APPROVAL}

The present study was approved by Ethics Committee for Animal Experimentation of the State University of Maringá, Paraná state, Brazil, under protocol number 080/2010.

\section{CORRESPONDENCE TO}

Luzmarina Hernandes, Laboratório de Histologia, Departamento de Ciências Morfológicas, Universidade Estadual de Maringá, Avenida Colombo 5790, Bloco H79, sala 108, Maringá, PR, 87020 900, Brasil. Phone: +55 4432614706. Fax:+55 443261 4340. Email: lhernandes@uem. br.

\section{REFERENCES}

1. Walsh TJ, Groll AH. Emerging fungal pathogens: evolving challenges to immunocompromised patients for the twenty-first century. Transpl Infect Dis. 1999;1(4): 247-61.

2. Musa MO, Al Eisa A, Halim M, Sahovic E, Gyger M,
Chaudhri N, et al. The spectrum of Fusarium infection in immunocompromised patients with haematological malignancies and in non-immunocompromised patients: a single institution experience over 10 years. Br J Haematol. 2000;108(3):544-8.

3. Nucci M, Anaissie EJ, Queiroz-Telles F, Martins CA, Trabasso P, Solza C, et al. Outcome predictors of 84 patients with hematologic malignancies and Fusarium infection. Cancer. 2003;98(2):315-9.

4. Cocuroccia B, Gaido J, Gubinelli E, Annessi G, Girolomoni G. Localized cutaneous hyalohyphomycosis caused by a Fusarium species infection in a renal transplant patient. J Clin Microbiol. 2003;41(2):905-7.

5. Boutati EI, Anaissie EJ. Fusarium, a significant emerging pathogen in patients with hematologic malignancy: ten years' experience at a cancer center and implications for management. Blood. 1997;90(3):999-1008.

6. Gupta AK, Baran R, Summerbell RC. Fusarium infections of the skin. Curr Opin Infect Dis. 2000;13(2):121-8.

7. Naiker S, Odhav B. Mycotic keratitis: profile of Fusarium species and their mycotoxins. Mycoses. 2004;47(1-2):50-6.

8. Godoy P, Nunes E, Silva V, Tomimori-Yamashita J, Zaror L, Fishman O. Onychomycosis caused by Fusarium solani and Fusarium oxysporum in São Paulo, Brazil. Mycopathologia. 2004;157(3):287-90.

9. Guilhermetti E, Takahachi G, Shinobu CS, Svidzinski TIE. Fusarium spp as agents of onychomycosis in immunocompetent hosts. Int J Dermatol. 2007;46(8):822-6.

10. Nelson PE, Dignani MC, Anaissie EJ. Taxonomy, biology, and clinical aspects of Fusarium species. Clin Microbiol Rev. 1994;7(4):479-504.

11. Conková E, Laciaková A, Kovác G, Seidel H. Fusarial toxins and their role in animal diseases. Vet J. 2003;165(3):214-20.

12. Evans J, Levesque D, Lahunta A, Jensen HE. Intracranial fusariosis: a novel cause of fungal meningoencephalitis in a dog. Vet Pathol. 2004;41(5):510-4.

13. McLean M. The phytotoxicity of Fusarium metabolites: an update since 1989. Mycopathologia. 1996;133(3):163-79.

14. Vesonder RF, Labeda DP, Peterson RE. Phytotoxic activity of selected water-soluble metabolites of Fusarium against Lemna minor L. (Duckweed). Mycopathologia. 1992;118(3):185-9.

15. Hartman CL, McCoy TJ, Knous TR. Selection of alfalfa (Medicago sativa) cell lines and regeneration of plants resistant to the toxin(s) produced by Fusarium oxysporum f. sp. medicaginis. Plant Sci Lett. 1984;34(12):183-94.

16. Patel JD, Patil MR, Sapkal PN. Toxic effect of culture filtrate of Curvularia lunata (Wakker) Boedijin and Alternaria tenuis Auct. PKV Res J. 1987;11(2):189.

17. Marangon AV, Svidzinski TI, Salci TP, Meurer R, da Cruz Fernandes M, Hernandes L. Metabolic extract of Fusarium oxysporum induces histopathologic alterations and apoptosis in the skin of Wistar rats. Int 
J Dermatol. 2009;48(7):697-703.

18. Melo IS, Picccinin E. Toxic metabolites from culture filtrate of Fusarium oxysporum and its effects on cucumber cells and plantlets. Rev Microbiol. 1999;30(2):104-6.

19. Costa MJN, Campos VP, Pfenning LH, Oliveira DF. Toxicidade de filtrados fúngicos a Meloidogyne incognita. Fitopatol Bras. 2001;26(4):749-55.

20. Ortoneda M, Guarro J, Madrid MP, Caracuel Z, Roncero MI, Mayayo E, et al. Fusarium oxysporum as a multihost model for the genetic dissection of fungal virulence in plants and mammals. Infect Immun. 2004;72(3):1760-6.

21. Tosti A, Piraccini BM, Lorenzi S. Onychomycosis caused by nondermatophytic molds: clinical features and response to treatment of 59 cases. J Am Acad Dermatol. 2000;42(2 Pt 1):217-24.
22. Nucci M, Anaissie E. Cutaneous infection by Fusarium species in healthy and immunocompromised hosts: implications for diagnosis and management. Clin Infect Dis. 2002;35(8):909-20.

23. Bodey GP, Boktour M, Mays S, Duvic M, Kontoyiannis D, Hachem R, et al. Skin lesions associated with Fusarium infection. J Am Acad Dermatol. 2002;47(5):659-66.

24. Duarte MLR, Archer SA. In vitro toxin production by Fusarium solani f. sp. Piperis. Fitopatol Bras. 2003;28(3):229-35.

25. Sugiura Y, Barr JR, Barr DB, Brock JW, Elie CM, Ueno $\mathrm{Y}$, et al. Physiological characteristics and mycotoxins of human clinical isolates of Fusarium species. Mycol Res. 1999;103(11):1462-8. 